\title{
Erratum to: Furazolidone, Co-amoxiclav, Colloidal Bismuth Subcitrate, and Esomeprazole for Patients Who Failed to Eradicate Helicobacter pylori with Triple Therapy
}

\author{
Zaigham Abbas $\cdot$ Javed Yakoob $\cdot$ Shahab Abid • \\ Wasim Jafri · Muhammad Islam $\cdot$ Zahid Azam . \\ Imran Hilal
}

Published online: 18 March 2010

(C) Springer Science+Business Media, LLC 2010

Erratum to: Dig Dis Sci (2009) 54:1953-1957

DOI 10.1007/s10620-008-0582-6

Shahab Abid has an additional affiliation, which was not listed in the original article. Please note the additional affiliation listed below.

The online version of the original article can be found under doi:10.1007/s10620-008-0582-6.

Z. Abbas $(\bowtie) \cdot$ J. Yakoob - S. Abid · W. Jafri · M. Islam · Z. Azam - I. Hilal

Department of Medicine, The Aga Khan University, Stadium Road, P.O. Box 3500, Karachi 74800, Pakistan

e-mail: zaigham@akunet.org

\section{S. Abid}

Karolinska Institutet, Department of Medicine,

Division of Gastroenterology and Hepatology, Karolinska

University Hospital Huddinge, Stockholm 14186, Sweden 